\title{
The changes of soft tissue profile in skeletal class II patients with mandibular retrognathy treated by the extraction of maxillary first premolars
}

\author{
Hendri, Tono S. Hambali, Jono Salim, Endah Mardiati \\ Department of Orthodontics, Faculty of Dentistry Universitas Padjadjaran
}

\section{ABSTRACT}

The purpose of this research is to measure the change of soft tissue profile, both antero-posteriorly as well as vertically in skeletal class II patients with mandibular retrognathy cases, treated with extraction of the maxillary first premolars. Pre and post treatment result of 16 patient treated with the Standard Edgewise fixed appliance were compared using a Canon D646u series scanner and Corel Draw 12 computer programme, utilizing the TVL line as plane of orientation. The result was analyzed with paired t-test. Statistical analysis show significant anteroposterior and vertical soft tissue changes in facial profile in skeletal class II patients with mandibular retrognathy treated with extraction of maxillary first premolars using the Standard Edgewise fixed appliance, measured with STCA-VTL method.

Key words: Soft tissue profile, skeletal class II with mandibular retrognathyc, extraction of two upper premolars, SCTA-TVL method

\section{INTRODUCTION}

The main objective of orthodontic treatment is to achieve balance functional occlusion and a harmonious facial esthetics. ${ }^{1}$ Generally, the patients motivation to get orthodontic treatment is because they have a dentition disarrangement and facial esthetic problems. The treatment performed is aimed, both directly and indirectly, at improving the patient's facial appearance or profile. $^{2}$

The relationship between the soft tissue profile with the facial esthetic and dental occlusion is still debatable. Some experts suggested that there is a relationship between dental occlusion and facial esthetics while the others refused this assumption. ${ }^{3}$ The results from a study on a group of beauty pageant queens in US shows that some of them have class II division I malocclusion. ${ }^{3}$

In skeletal class II malocclusion, there is a gap in the relationship of the jaws in the anteroposterior perspective. A skeletal class II malocclusion may happen due to lower jaw retrognathy with a normal upper jaw, upper jaw prognathy and normal lower jaw, or combination of the two where there is an upper jaw prognathy and lower jaw retrognathy. ${ }^{4}$ Proffitt ${ }^{5}$ said that class II malocclusion might be caused by dentoalveolar, skeletal or neuro-muscular abnormalities with the skeletal factor as the most common factor. A research in the United States proved that almost all class II malocclusion cases are caused by abnormal lower jaw growth. Moyers ${ }^{6}$ stated that the skeletal class II malocclusion may 
happen horizontally, vertically and transversally. The horizontal abnormality is caused by the relationship of maxilla towards a normal cranium with retrognathic mandible that creates big overjet. It may happen that there is a prognathic maxilla and normal mandible with large or normal overjet. A more severe condition is found when there is a prognathic maxilla and a retrognathic mandible. Bishara ${ }^{7}$ stated that the vertical abnormality in skeletal class II malocclusion is due to an abnormal vertical growth of the maxilla and mandible so that the lower facial height is shorter than the upper facial height. The transversal abnormality may be caused by a maxillary palatal arch that is narrower than the mandible arch. ${ }^{7}$

Class II division 1 malocclusion has a main signs that include large overjet, deepbite and hyperactive mentalis muscle. ${ }^{6}$ The overjet will become more severe when there is a large anteroposterior discrepancy between the maxillary dentition and the mandibular dentition. Deepbite is found due to a mandibular rotation upward and forward, excessive lower incisive eruption or insufficient posterior teeth eruption. ${ }^{5}$ According to Karlsen ${ }^{8}$, in patients with class II division 1 malocclusion that is accompanied by deepbite, the lower anterior facial height is smaller than those without deepbite. The deepbite in patients is marked by increased upper anterior facial height. However, in patients with open bite, an increased lower anterior facial height is found. ${ }^{9}$

There are three types of treatment that can be used to treat class II malocclusion, i.e. growth modification, compromised treatment and orthognathic surgery. A skeletal growth modification treatment and orofacial functional treatment can be performed to patients who are still growing. The compromised treatment is aimed more on fixing dental disarrangement and interjaw dental relationship without correcting the skeletal part while the surgery treatment is aimed at fixing jaw relationship through orthognathic surgery approach. ${ }^{10}$

The compromised treatment for skeletal class 2 division I malocclusion is generally conducted through extracting two upper premolars to retract six anterior teeth. This action is performed to reduce large overjet and to improve patient's facial esthetic profile. ${ }^{5}$ The changes in the facial vertical height after orthodontic treatment with premolar extraction often trigger controversy among researchers. Some researchers stated that extracting premolar to retract anterior teeth may lead to decreased facial vertical height while others believe that there is no change. ${ }^{11}$

There are various ways to judge facial esthetics, including using radiograph by assessing soft tissue related to facial profile using lateral cephalogram. ${ }^{2}$ To find out if there is a change in soft tissues in terms of orthodontic treatment, some analyses of profile, lips and tongue can be performed. A lot of experts suggest to use soft tissue analysis as a trusted guideline to assess orthodontic treatment results. ${ }^{1}$

There are several analysis that can be used to evaluate lips posture and soft tissue profile esthetics. Each analysis has advantages and disadvantages. Rickett's "E" line is very much affected by nasal soft tissue growth. Steiner's " $S$ " line ignores integumental profile changes due to nasal growth. Holdaway's "H" line ignores the effects of nasal growth in evaluating lips posture. Merrifield " $Z$ " angle shows lip protrusion in malocclusion cases. ${ }^{12}$ Viaziz "V" angle can show profile convexity because it is concentrated in facial lower half part. ${ }^{13}$ This measurement can be done manually or by using computer programs.

Recently, the use of computer programs in orthodontic analysis has grown rapidly. One of the programs is STCA (Soft Tissue Cephalometric Analysis). STCA is an analysis for facial soft tissue cephalometry that can be used to diagnose five different facial areas that are interconnected. The areas include dentoskeletal, soft tissue component, facial height, TVL projection and facial harmony parts. The STCA is made in a position where the head is in line with the floor and the lips are passive. ${ }^{14}$

One of the STCA measurement is the TVL from Arnett et al. ${ }^{14}$ TVL (true vertical line) is used to measure soft tissue anteroposterior and the distance of the dentoskeletal position combined with the thickness of soft tissue that lines the hard tissue landmark. The horizontal distance of the facial soft tissue profile for each individual that is measured towards TVL is called the absolute landmark value. The advantage of using this TVL is that this line is not affected by soft tissue growth because this line is made perpendicular towards Frankfort Horizontal Plane. ${ }^{14,15}$ 


\section{MATERIALS AND METHODS}

The instruments used in this study include: illuminator lamp, acetate paper, $4 \mathrm{H}$ pencil, eraser, computer and Corel Draw software, and scanner.

The study performed at Orthodontic Specialist Programme Clinic of the Faculty of Dentistry, Universitas Padjadjaran Bandung between January and April 2007.

The population for this study is skeletal class II malocclusion patients with mandibular retrognathy and normal maxilla treated using Edgewise Standard from 1997 to 2006.

The sample in this study consist of 16 skeletal class II malocclusion patients with the following criteria: Age, 16-25 years; sex, male and female; malocclusion criteria, skeletal class II with mandibular retrognathy $\left(\mathrm{SNB}<78^{\circ}\right)$ and normal maxilla (SNA 82 \pm 2 ); camouflage treatment in skeletal class II malocclusion patients with mandibular retrognathy and normal maxilla with two upper premolar extraction and Edgewise Standard orthodontic treatment technique.

The 32 cephalograms were divided into 16 pre-treatment cephalograms and 16 posttreatment cephalograms. The cephalograms were then coded. The next step was facial soft tissue tracing for each cephalogram. Each tracing result was then scanned using Canon D646u scanner. Orientation lines and points were then determined, FHP line was made and then TVL line that is perpendicular to FHP was determined. The TVL was placed through $\mathrm{N}$ point. The facial balance (profile) measurement using TVL method (Arnett) was performed by measuring the distance between the upper lips and lower lips to TVL line using Corel Draw 12 software. The tracing and measurement for each cephalogram was done twice with 1 week interval for data calibration. All data was noted and analyzed.

The anatomical points used in this study are TVL (True Vertical Line) which is a line through subnasal and perpendicular to FHP $\left(7^{\circ}\right.$ from SN line). In this study, the TVL line is placed through $\mathrm{N}$ point. NT (Nose tip) is the tip of the nose in the midline area. Sn (Subnasale) is a point in nasal septum that connect nostril and upper lips to midline. A' point is the deepest point of upper lip midline between the subnasal and labiale superius. ULA (upper lip anterior) is an upper margin central point in upper lip membrane. LLA (lower lip anterior) is the midpoint in lower lip membrane margin. Point $B^{\prime}$ is the deepest point in the lower lip midline between labiale inferius and soft tissue pogonion. Pog' is the most prominent anterior point in chin soft tissue in the midsagittal area. Point $\mathrm{Na}$ ' is the $\mathrm{Na}$ (Nasion) point projection in the facial soft tissue. Point Me' is a projection of Me (Menton) point of the facial soft tissue. ULL is the upper lip length. LLL is the lower lip length. Facial height is the height of the face measured from point $\mathrm{Na}$ ' (Nasion point projection in soft tissue) to Me' (Menton point projection in soft tissue).

\section{RESULTS}

\section{Average changes in anteroposterior soft tissue profile}

The results of the study data analysis on the changes in anteroposterior profile change in 16 patients before and after treatment are listed in Table 1. It is apparent that the nose tip (NT), upper lip anterior (ULA) and lower lip anterior (LLA) points as well as the deepest point in the upper lip midline between subnasal and labiale superius ( $\left.A^{\prime}\right)$, the deepest point of the lower lip midline between labiale inferius and pogonion of the soft tissue ( $B^{\prime}$ ) and the most prominent anterior point in chin soft tissue in the midsagittal (Pog'),

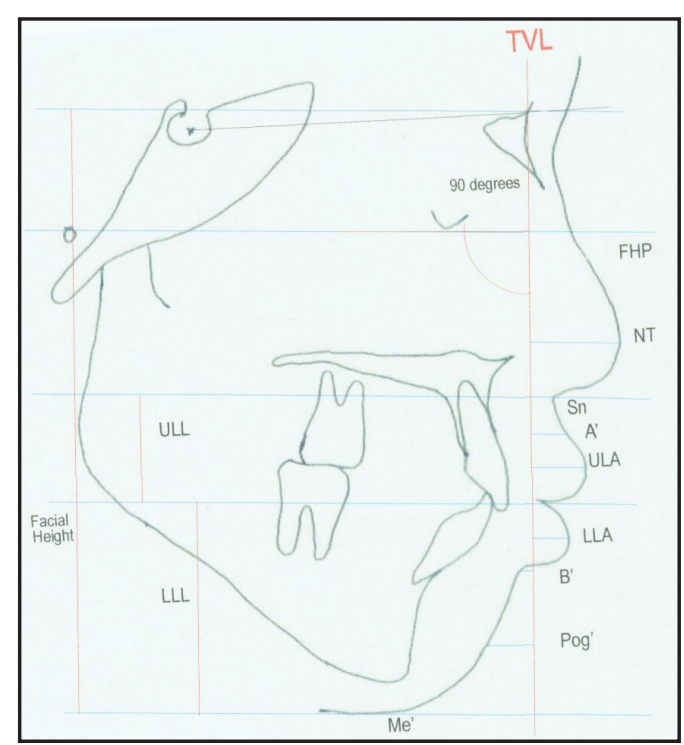

Figure 1. Line and orientation points of anteroposterior profile and vertical point of the facial soft tissue measurement towards the TVL line used in the study. 
Table 1. Average distance of anteroposterior facial soft tissue to TVL line before and after treatment.

\begin{tabular}{ccccc}
\hline Point of orientation & Before $(\mathrm{mm})$ & After $(\mathrm{mm})$ & Average change & SD \\
\hline NT & 27.92 & 27.39 & 0.84 & 0.88 \\
ULA & 19.35 & 15.84 & 3.88 & 3.08 \\
LLA & 15.35 & 11.11 & 5.27 & 4.13 \\
A & 15.81 & 12.66 & 3.36 & 3.19 \\
B & 7.13 & 3.90 & 4.44 & 4.00 \\
Pog & 4.93 & 2.16 & 4.40 & 3.87 \\
\hline
\end{tabular}

Note: NT (Nose tip); ULA (Upper Lip Anterior); LLA (Lower Lip Anterior); A' (the deepest point of upper lip mid-line between sub nasal and labiale superius); B' (the deepest point of upper lip mid-line between labiale inferius and soft tissue pogonion); Pog' (the prominent anterior point of the chin soft tissue at the midsagital plane).

Table 2. Average distance of anteroposterior facial hard tissue to TVL line before and after treatment.

\begin{tabular}{ccccc}
\hline Point of orientation & Before $(\mathrm{mm})$ & After $(\mathrm{mm})$ & Average changes & SD \\
\hline A & -1.67 & -1.65 & 1.56 & 1.81 \\
B & -12.86 & -15.85 & 4.39 & 3.94 \\
I-RA & 5.52 & 0.08 & 5.97 & 4.73 \\
I-RB & 1.23 & -2.47 & 4.60 & 3.87 \\
Pog & -16.46 & -17.75 & 4.84 & 4.66 \\
\hline
\end{tabular}

Note: A (Subspinal); B (Supramental); I RA (Maxilla incisor edge); I RB (Mandible incisor edge); Pog (Pogonion).

Table 3. Average changes in facial soft tissue height after treatment.

\begin{tabular}{ccccc}
\hline Point of orientation & Before $(\mathrm{mm})$ & After $(\mathrm{mm})$ & Average changes & SD \\
\hline Face height & 134.04 & 136.16 & 4.91 & 3.29 \\
ULL & 27.41 & 27.39 & 1.37 & 1.32 \\
LLL & 45.67 & 47.09 & 2.79 & 2.59 \\
\hline
\end{tabular}

Note: ULL: Upper Lip Length; LLL: Lower Lip Length.

experience changes before and after fixed orthodontic treatment

In Table 2 there are A, B, I RA, I RB and Pog points that experience changes before and after a fixed orthodontic treatment.

In Table 3 it is apparent that the facial vertical height in patients with skeletal class II malocclusion and mandibular retrognathy and normal maxilla with upper premolar extraction treated using Edgewise Standard technique experiences changes after treatment.

\section{DISCUSSION}

Average changes in antero-posterior facial soft tissue profile

The results of this study on the anteroposterior facial soft tissue profile measurement show that there are significant changes after fixed orthodontic treatment with upper premolar extraction. The average changes in nose tip (NT) is $0.84 \mathrm{~mm}$, upper lip anterior (ULA) is $3.88 \mathrm{~mm}$, lower lip anterior (LLA) is 5.27 $\mathrm{mm}$, the deepest upper lip midline point $\left(A^{\prime}\right)$ is $3.36 \mathrm{~mm}$, the deepest lower midline point (B') is $4.44 \mathrm{~mm}$, the most anterior point of the chin (Pog') is 4.40 .

Kocadereli ${ }^{18}$ stated that the premolar extraction followed by canine distalization and incisive retraction will cause changes in lip tissue position and will reduce lip convexity. The incisive movement towards sagittal direction creates changes in soft tissue of $60-70 \%$ from the incisive total movement ${ }^{5}$, showing that each anterior dental retraction will cause changes in soft tissue. Nanda' study shows that upper incisive retraction of $3.1 \mathrm{~mm}$ causes the upper lips to move backward $1.9 \mathrm{~mm}$. The result of this study shows that the upper incisive point (UIP) changes in average of $5.97 \mathrm{~mm}$, Subspinal point (A) of $1.56 \mathrm{~mm}$, Supramental point (B) of $4.39 \mathrm{~mm}$, lower incisive (LC) of $4.60 \mathrm{~mm}$, Pogonion (Pog) of $4.48 \mathrm{~mm}$. 
In this study, the upper incisive point change ratio and upper lip anterior point is 5.97:3.88 mm (IRA:ULA = 1:0.65). The comparison of upper incisive average changes with Subspinal A point that experience changes of $1.56 \mathrm{~mm}$ is IRA:A=1:0.26. The comparison of upper incisive average changes with point $A^{\prime}$ that experiences an average change of $3.36 \mathrm{~mm}$ is IRA: $\mathrm{A}^{\prime}=1: 0.56$. The changes in the location of upper lip anterior (ULA) and lower lip anterior (LLA) points are big enough approaching TVL line showing that there is a change in facial anteroposterior profile convexity.

Talass $^{16}$ research on the correlation of the incisive position changes and lip position changes in 133 white women with skeletal class II division 1 malocclusion shows that upper incisive retraction average of $6.7 \mathrm{~mm}$ will cause the upper lip to move backward for an average of $4.3 \mathrm{~mm}$. In this study, there are changes in upper incisive point of $5.97 \mathrm{~mm}$, causing changes in upper lip anterior point of $3.88 \mathrm{~mm}$.

\section{Average changes in facial vertical height after a fixed orthodontic treatment}

The results of the study show that there is some vertical dimension changes. The average of facial height change is $4.91 \mathrm{~mm}$, upper facial height (ULL) is $1.37 \mathrm{~mm}$, lower facial height (LLL) is $2.79 \mathrm{~mm}$. This is in line with Nanda9 study that showed for treatment of deepbite patients with short lower anterior facial height, a vertical dimension addition can be attained by extracting posterior teeth. In this research, a facial vertical height increase is found. The facial vertical height changes after the orthodontic treatment with premolar extraction is still a controversy among researchers. ${ }^{11}$ The study performed by Chua et al. ${ }^{17}$ shows that lower anterior facial height changes may happen without premolar extraction while treatment with premolar extraction does not cause lower anterior facial height change.

The results of $\mathrm{Kim}^{11}$ study in fixed orthodontic treatment case with two first premolar extractions show changes in facial soft tissue vertical profile, total facial height $\left(\mathrm{N}^{\prime}\right.$ Me') that, in average, increases $3.44 \mathrm{~mm}$, lower anterior facial height (ANS'-Me') increases 2.06 $\mathrm{mm}$, upper anterior facial height increases ( $\mathrm{N}^{\prime}$. ANS') $1.39 \mathrm{~mm}$. Kodaracelli ${ }^{18}$ stated that first premolar extraction in orthodontic treatment will cause anterior facial height changes. The anterior facial height becomes higher $4.67 \mathrm{~mm}$ while lower anterior facial height (ANS-Menton) experiences a change of $2.93 \mathrm{~mm}$ higher after treatment with first premolar extraction is performed. The orthodontic treatment with first premolar dental extraction leads to increased lower facial anterior height that will affect the total facial height. ${ }^{19}$

\section{CONCLUSION}

There were alterations of soft tissue and anteroposterior facial profile in skeletal class II malocclusions in patients with mandibular retrognathy and normal maxilla before and after extraction of two upper premolar treated using Edgewise Standard fixed orthodonthics. The alteration of facial anterior-posterior before and after treatment has a rather high value. Therefore, it is better that before the treatment the operator explains the possible changes in patient's anterior-posterior soft-tissue and facial vertical profile through cephalometer soft and hard tissue analysis using the TVL methods, to prevent complaints at the end of treatment from the patient. Further research more samples is needed in order to be used as a standard for Indonesian people.

\section{REFERENCES}

1. Turkkahraman H. Facial profile preference among various layer of Turkish population. Angle Orthod 2004;74:640-7.

2. Rakosi T. An atlas and manual of cephalometric radiography. Great Britain: Wolfe Medical Publications Ltd.; 1982. p. 94-5.

3. Holdaway RA. A soft tissue cephalometric analysis and its use in orthodontic treatment planning. Part I. Am J Orthod Dentofac Orthop 1983;8:1-28.

4. Graber TM. Dentofacial orthopedics with functional appliances. St. Louis: Mosby-Year Book Inc; 1997. p. 471-51.

5. Profitt WR, Fields HW. Contemporary orthodontics. St Louis: The C.V. Mosby Inc.; 2000.

6. Moyers RE. Hand book of orthodontics. Chicago: Year Book Medical Publisher Inc.; 1988.

7. Bishara SE. Text book of orthodontics. Pensylvania: W.B. Saunders Co.; 2001. 
8. Karlsen AT. Craniofacial morphology in children with Angle class II-I malocclusion with and without deepbite. The Angle Orthodontist 1994;64(6):437-46.

9. Nanda R. Biomechanics in clinical orthodontics. Philadelphia: W.B. Saunders Co.; 1997. p. 235.

10. Pfeiffer JP, Grobety D. A Philosophy of combined orthopedic-orthodontic treatment. Am J Orthod Dentofac Orthop 1982;81:185200.

11. Kim Tae-Kyung. First or second premolar extraction effect on facial vertical dimension. The Online Angle Orthodontist 2004;75:17782.

12. Oliver BM. The influence of lip thickness and strain on upper lip response to incisor retraction. Am J Orthod Dentofac Orthop 1982;82:141-9.

13. Viaziz AD. A new measurement of profile esthetics. J Clin Orthod 1991;25:15-20.
14. Arnett GW. Soft tissue cephalometric analysis: diagnosis and treatment planning of dentofacial deformity. Am J Orthod Dentofac Orthop 1999;116:239-53.

15. MC Laughlin PM, Bennet JC, Trevisi HJ. Systemized orthodontic treatment mechanics. St. Louis: Mosby; 2001.

16. Talass MF, Tallas L, Baker RC. Soft-tissue profile changes resulting from retraction of maxillary incisor. Am J Orthod Dentofac Orthop 1987;91:385-94.

17. Chua Ai-Lian. The effect of extraction versus nonextraction orthodontic treatment on the growth of the lower anterior face height. Am J Orthod Dentofac Orthop 1993;104:361-8.

18. Kocadereli. The effect of first premolar extraction on vertical dimension. Am J Orthod Dentofac Orthop 1999;116:41-5.

19. Stagger JA. Vertical change following first premolar extraction. Am J Orthod Dentofac Orthop 1994;105:19-24. 